\title{
PROXIMIDADE AFETIVA NO RELACIONAMENTO PROFISSIONAL-PACIENTE NO TRATAMENTO DOS TRANSTORNOS ALIMENTARES
}

\author{
Laura Vilela e Souza ${ }^{1}$ \\ Universidade Federal do Triângulo Mineiro, Uberaba-MG, Brasil \\ Manoel Antônio dos Santos \\ Universidade de São Paulo, Ribeirão Preto-SP, Brasil
}

\begin{abstract}
RESUMO. Poucos espaços são oferecidos para escuta de como pacientes diagnosticados com transtornos alimentares entendem o discurso que preconiza a necessidade de distanciamento afetivo entre profissional e paciente. Buscamos compreender de que modo o pedido dos pacientes por maior proximidade afetiva em relação ao profissional de saúde pode participar da construção do bom relacionamento com médicos, psicólogos e nutricionistas. Pacientes de um serviço de assistência em transtornos alimentares foram entrevistados. A análise do material baseou-se na proposta teóricometodológica das práticas discursivas e produção de sentidos sustentada pelo discurso construcionista social. Foram destacados os sentidos e discursos e os jogos de posicionamentos implicados nessas produções discursivas. As participantes construíram a proximidade com o profissional como ingrediente fundamental para uma possível superação do transtorno. Os argumentos a favor de um contato mais íntimo com os profissionais e o uso do discurso da neutralidade pelo profissional foram problematizados em seu contexto de produção.
\end{abstract}

Palavras-chave: Profissionais da saúde; anorexia nervosa; bulimia.

\section{EMOTIONAL APPROXIMATION IN THE PROFESSIONAL-PATIENT RELATIONSHIP IN THE TREATMENT OF EATING DISORDERS}

\begin{abstract}
Few spaces are available for listening how patients diagnosed with eating disorders understand the discourse of a need for an emotional distance between professional and patient. We seek to understand how the request made by patients for greater emotional bonding with the health professional can participate in building a good relationship with doctors, nutritionists and psychologists. Patients from a service of assistance in eating disorders were interviewed. The theoretical and methodological proposal of discursive practices and meanings production, underpinned by a social constructionist discourse, guided the analysis of the material. Discourses, meanings and positioning games involved in these discursive productions were highlighted. Participants constructed their proximity to the professional as a key ingredient for overcoming the disorder. The arguments in favor of a more intimate contact with the professionals and the use of the discourse of neutrality by the professional were discussed in its context of production.
\end{abstract}

Key words: Health professionals; anorexia nervosa; bulimia.

\section{PROXIMIDAD AFECTIVA EN LA RELACIÓN PROFESIONAL-PACIENTE EN EL TRATAMIENTO DE LOS TRASTORNOS ALIMENTARIOS}

RESUMEN. Pocos son los espacios para escuchar cómo los pacientes diagnosticados con trastornos alimentarios entienden el discurso que preconiza la necesidad de alejamiento afectivo entre el profesional y el paciente. Tratamos de entender cómo la solicitud por parte de los pacientes por mayor proximidad afectiva en relación al profesional de salud puede participar de la construcción de una buena relación con médicos, psicólogos y nutricionistas. Los pacientes de un servicio de asistencia en trastornos alimentarios fueron entrevistados. La

1 Endereço para correspondência: Universidade Federal do Triângulo Mineiro, Av. Getúlio Guaritá, 159, Centro Educacional, Sala 320 Bairro: Abadia, CEP 38025-180, Uberaba - MG, Brasil. Email: lauravilelasouza@gmail.com 
propuesta teórico-metodológica de las prácticas discursivas y la producción de sentidos, defendida por el discurso construccionista social, orientó el análisis del material. Se destacaron los sentidos y discursos y los juegos de posicionamiento que participan en dichas producciones discursivas. Las participantes construyeron la proximidad con el profesional como ingrediente fundamental para una posible superación del trastorno. Los argumentos a favor de un contacto más íntimo con los profesionales y el uso del discurso de la neutralidad por el profesional fueron problematizados en su contexto de producción.

Palabras-clave: Profesionales de la salud; anorexia nerviosa; bulimia.

Bruch (1978), uma das pioneiras na elaboração de uma proposta psicoterápica específica para o campo dos transtornos alimentares (TAs), havia chamado a atenção para a necessidade de que o profissional, ao atender pessoas diagnosticadas com anorexia nervosa (AN) e bulimia nervosa $(B N)$, realizasse adaptações técnicas no seu trabalho, considerando as características do funcionamento psicopatológico desses pacientes. Para Jeammet (2003), a teoria psicanalítica dá suporte à defesa do pressuposto de que esses pacientes são especialmente "dependentes" dos profissionais que deles cuidam, tendo dificuldade em encontrar a distância relacional correta (p. 112). Dessa forma, o terapeuta se vê, nas palavras do autor, "desafiado" e "confrontado" em seus "limites" como profissional. Outro psicanalista, Brusset (2003), também argumenta a favor da boa distância que deve existir entre o profissional e o paciente com TA e defende a postura de neutralidade. Uma boa distância nesse relacionamento, segundo o autor, deveria mostrar o interesse do profissional pelo paciente e ao mesmo tempo evitar uma maior proximidade.

O discurso biomédico, influenciado pelo dualismo cartesiano, marca esse relacionamento a partir da cisão entre o mundo físico e o mundo subjetivo do paciente. Sendo assim, alguns profissionais - como o médico - deveriam cuidar dos aspectos biológicos do paciente diagnosticado com $\mathrm{AN}$ ou $\mathrm{BN}$, enquanto $\mathrm{O}$ psicólogo deveria manter o foco nos aspectos emocionais. Neste cenário, o fazer médico pode prescindir da consideração dos aspectos abstratos da "subjetividade humana" (Pessotti, 1996). Ao mesmo tempo, essa alienação profissional responde a uma formação acadêmica - dominante nos cursos de medicina que muitas vezes prepara o futuro médico para lidar com "um paciente padrão, um paciente teórico, virtual" (p. 443).
A perspectiva construcionista social aponta para o caráter socialmente construído das teorias e discursos sobre os TAs, problematizando os efeitos que as teorias psicanalíticas apontadas, assim como o discurso biomédico, têm na construção de uma visão negativa do relacionamento do profissional com os pacientes com AN e BN. Esses discursos se refletem na caracterização desses pacientes como difíceis, refratários e insubmissos, bem como na construção do distanciamento afetivo entre o profissional e o paciente (Hepworth, 1999). É possível perceber que não é apenas na literatura referente às práticas psicoterapêuticas que o relacionamento entre o profissional e o paciente aparece permeado por dificuldades. Williams e Leicher (2006) afirmam que grande parte dos profissionais que trabalham com TA relata vivenciar sentimentos negativos ao atender os pacientes, chegando inclusive a preferir não mais atuar na área. Satir e cols. (2009) afirmam que os profissionais consideram difícil manejar as reações emocionais intensas dos pacientes durante os atendimentos. Ao estudar as razões da sobrecarga emocional dos enfermeiros que trabalham em serviços de tratamento da AN, George (1997) advoga a necessidade de que esses profissionais recebam treinamento específico antes de terem contato com essas pacientes e tenham supervisões regulares para poderem lidar com seus comportamentos difíceis.

$\mathrm{Na}$ perspectiva construcionista-social a proximidade afetiva é tomada como construção social, apreciada a partir de sua funcionalidade nos relacionamentos; ou seja, diferentemente do discurso tradicional em ciência, não se espera o alcance de uma verdade universal, sustentada por achados empíricos, sobre qual seja a distância afetiva ideal entre o profissional e o paciente. Neste caso $o$ foco recai no entendimento de quais são os sentidos de mundo e pessoa que sustentam a defesa das diferentes formas de esse relacionamento acontecer e quais alternativas podem ser 
exploradas. Poucos espaços têm sido oferecidos nos serviços de saúde para a escuta de como os pacientes entendem o discurso que defende a necessidade de distância afetiva entre 0 profissional e o paciente. Segundo Pettersen e Rosenvinge (2002). os pacientes mencionaram como relevante perceber que o profissional se importava com eles. De forma análoga, em estudo anterior, convidamos os pacientes a dialogarem sobre suas relações com os profissionais de saúde, e os participantes apontaram como importante aspecto qualificador dessas relações a proximidade afetiva do profissional com o paciente (Souza, 2011).

Alguns autores buscaram conhecer os efeitos positivos que a maior proximidade entre o profissional e o paciente poderia exercer sobre a qualidade do relacionamento e a busca da melhora. Tantillo (2004) sugere a possibilidade de o terapeuta revelar aspectos de sua vida pessoal como forma de favorecer o estabelecimento de melhor vínculo com o paciente com AN e BN, potencializando sua melhora. Rabinor (2004) menciona como ela, enquanto psicoterapeuta, pôde experimentar os efeitos benéficos de um abraço oferecido a uma paciente com AN durante um de seus atendimentos. Já no âmbito dos cuidados de enfermagem, George (1997) aponta que, para o relacionamento com pacientes com TA ser positivo, o profissional deve ser capaz de "aceitar" verdadeiramente a pessoa e fazer de seus encontros ambientes de "proximidade", "empatia", "confiança", "compromisso" e de relacionamento genuíno.

Diante dessas considerações, buscamos no presente estudo compreender de que modo o pedido dos pacientes por maior proximidade afetiva com o profissional de saúde pode participar da construção do bom relacionamento entre o profissional e o paciente.

\section{MÉTODO}

Todos os pacientes atendidos por pelo menos um ano no ambulatório de assistência em transtornos alimentares de um hospital-escola foram convidados a participar da pesquisa. A escolha desse intervalo temporal buscou garantir que os participantes tivessem uma história consolidada de relacionamento com os profissionais do serviço. No período definido para a coleta de dados, de janeiro de 2008 a junho de 2008, doze mulheres, com idades entre 13 e 45 anos, aceitaram participar da pesquisa e formalizaram sua anuência mediante a assinatura do Termo de Consentimento Livre e Esclarecido. O projeto foi aprovado pelo Comitê de Ética em Pesquisa com Seres Humanos da instituição (protocolo n. 7310/2007). Foram utilizados pseudônimos para resguardar a identidade das participantes e dos profissionais referidos em seus relatos.

Como parte de uma pesquisa mais ampla, que buscava conhecer como os pacientes avaliavam a assistência oferecida e as relações estabelecidas com os profissionais e seus familiares durante o tratamento, foram realizadas entrevistas individuais semiestruturadas durante um encontro único com cada participante do estudo, abordando os seguintes temas: "O que é o transtorno alimentar"; "Como se deu a acolhida no serviço"; "O que ajuda durante a internação"; "O relacionamento entre a família e o paciente"; "O relacionamento entre 0 profissional 0 paciente". No presente estudo foi feito um recorte, focalizando a análise do relacionamento entre o profissional e o paciente.

A entrevistadora era psicóloga do serviço. As entrevistas foram audiogravadas em fitas K7 e posteriormente transcritas na íntegra e literalmente. A proposta das delimitações temático-sequenciais de Rasera e Japur (2003) foi adaptada para análise do corpus da pesquisa e utilizada para o reconhecimento dos momentos em que o tema do relacionamento entre o profissional e o paciente se fez presente. Para este estudo, selecionamos as entrevistas de três participantes que abordaram a questão da proximidade afetiva com médicos, psicólogos e nutricionistas. Uma delas abordou esse tema em dois momentos de sua entrevista e as demais em apenas um momento. Essas participantes foram: Natássia, 18 anos, em atendimento havia três anos, diagnóstico de BN; Talia, 19 anos, em tratamento havia dois anos e meio, diagnóstico de BN; Ilda, 45 anos, em tratamento havia 12 anos, com diagnóstico de AN.

A análise foi orientada pela proposta teóricometodológica das práticas discursivas e de produção de sentidos, sustentada pelo discurso construcionista-social (Spink \& Medrado, 2000). Nessa proposta, a apresentação da entrevista deve preservar na íntegra a sequência de falas entre entrevistador e entrevistado, de modo a garantir a contextualização da produção de sentidos. Na análise dos recortes selecionados, 
destacamos os sentidos e discursos utilizados na coconstrução do pedido de maior proximidade afetiva com o profissional de saúde, bem como os jogos de posicionamentos entre o profissional e o paciente implicados nas produções discursivas.

\section{RESULTADOS}

\section{Natássia (1)}

Natássia contou que havia comprado laxantes para perder peso. A entrevistadora perguntou a razão para ela ter tomado essa decisão. Natássia respondeu:

\begin{abstract}
Natássia: Eu fiquei muito arrasada porque a Linda deixou de ser a minha nutricionista, mas, assim, demais. Eu dei escândalo, eu gritei, eu fiz e tal. Depois eu mudei o meu método: fiquei tranquila, falei para ela que tudo bem, só que, assim, é mentira. Não está tudo bem. Eu ainda estou muito mal com isso. Ai, eu não quero chorar! Eu ainda estou muito mal com isso, e tal. Eu acho que eu tive uma recaída depois disso, e aí eu comecei a chutar o balde, sabe? Tipo, é como se o único lugar com que eu tivesse contado... Tipo, ela cuidava muito de mim, sabe? Ela representava na minha vida mais que uma mãe. A gente chegou a ter muito problema com isso, porque eu acabei me apegando muito nela.
\end{abstract}

$\mathrm{Na}$ época em que a entrevistadora realizou as entrevistas para este estudo, uma das nutricionistas passou a assumir outra função dentro do serviço e, por essa razão, deixou de atender as pacientes. Ocorre que essa nutricionista, Linda, era muito querida por elas. Assim, é a partir do entendimento dessa interanimação dialógica que é possível compreender o uso dos diferentes sentidos para o consumo abusivo de laxante trazidos por Natássia. O sofrimento de Natássia foi, em seu discurso, associado ao afastamento de Linda de seu atendimento. Ao posicionar Linda como alguém que Ihe oferecia "o único lugar" no qual podia contar com alguém, o uso de laxante, o "escândalo", a "recaída" e o "chute no balde" foram recursos construídos como respostas à substituição indesejada da nutricionista. Essa narrativa parecia convidar a entrevistadora a ver o rompimento unilateral desse vínculo como um evento adverso e nocivo para o andamento de seu tratamento. Considerando-se o discurso da distância necessária entre profissional e paciente, na narrativa de Natássia a forma como a relação de apego foi construída no vínculo com Linda foi compreendida como um efeito colateral indesejado no relacionamento entre as duas.

\section{Natássia (2)}

O momento privilegiado no segundo recorte da entrevista da participante iniciou-se logo após a entrevistadora e Natássia conversarem sobre como Natássia imaginava que poderia ser um serviço ideal de tratamento de TAs. Ela afirmou que uma das características importantes seria que os retornos ambulatoriais das pacientes fossem menos espaçados. No suplemento oferecido pela entrevistadora, esse pedido de retornos menos espaçados foi construído como um possível pedido de maior "proximidade" da paciente com os profissionais do serviço. Natássia respondeu a esse sentido:

Natássia: Ah, é a pessoa. A Linda é demais! Por mais que eu tente odiar ela, sabe? Ai, para mim é muito difícil falar dela [se emociona]. Eu sinto muita falta dela, nossa! Ela me tratava assim... Aí eu falo: "Nossa, que saudade da Linda!", sabe? Tipo, quando eu estava mal, tudo, ela super me ajudava, entendeu? Eu saía daqui bem! Não que os outros profissionais não façam. Eles se esforçam, mas ela é a pessoa que mais me conhece. Eu falava coisas para ela que ninguém sabia, entendeu? $E$ ela entendia e ela conversava... Só porque eu cheguei que começaram com essas frescuras [referindo-se aos limites colocados pela equipe], eu pedi para ela... que ela podia deixar de ser a minha nutricionista e ir para a minha vida, sabe? Como uma pessoa normal. E ela ficou... Com toda aquela ética idiota, ela não... E eu falei assim: "E se eu tiver alta? Poxa, eu faço qualquer coisa". "Enfio aquela coisa na minha garganta, paro de vomitar, se eu puder ter você". Daí ela: "Não, também não vai". Então assim, eu gostaria de ter as pessoas na minha vida. Eu odeio ter um transtorno alimentar também por causa disso, sabe? Por quê que eu passo com a Linda, entendeu? Eu passo com a Linda porque eu tenho um transtorno alimentar. Se eu não tivesse, se eu fosse 
normal, eu poderia encontrar ela na rua e conhecê-la. Conhecer a pessoa, entendeu? Tipo, a Teresa [outra profissional do serviço] não tem essa ética idiota que ela [Linda] tem. Com a Teresa, a gente conversa quase todo o dia por e-mail... Só que quando eu percebi que eu estava me apegando muito nela, aí eu sumi, que aí eu fiquei mais de uma semana sem falar com ela no e-mail. Por mais que eu já deixei bem claro, que por mais que um dia eu saia daqui e a gente possa continuar se vendo, é que nem ela disse: nem todo mundo é igual, né. Cada um tem a sua ética, né? Quem disse que ela está certa e eu estava errada? Quem disse que a Linda está certa ou errada? Eu entendo, mas me dói.

Entrevistadora: Natássia, pensando em tudo isso, nessa experiência que você tem de quatro anos, né, qual que você acha que seria a melhor relação profissional possível? Essa que você está tendo com a Teresa, seria assim?

Natássia: Ah, eu acho que essa da Teresa, sabe?

Entrevistadora: O quê que ela tem que é diferente, que é ideal para você assim?

Natássia: $A i$, isso não vai fazer ela mudar não, né? Porque vai que algum... O que é top descobre e aí ele faz ela parar! Aí eu me jogo! A Teresa, ela é fantástica. Ela... A hora que eu preciso dela ela, está ali, entendeu? Tipo... Eu não sei se você chegou a ver, tipo, acabou o grupo, ela falou assim: "Ai, florzinha, eu preciso de você!". Ela é uma pessoa que, sabe, muitas vezes acabava o grupo, ela ficava comigo porque ela via que eu não estava bem.

Natássia relacionou a ajuda que Linda fora capaz de lhe oferecer com a possibilidade que teve de falar de si com a nutricionista. Dessa maneira, o sentido do cuidado ofertado pelo profissional foi agora relacionado a algo que aconteceu na relação entre as duas. A fala da equipe de que Natássia não poderia mais conversar com a nutricionista sobre aspectos que não tivessem estreita relação com seu problema alimentar levou, considerando o argumento construído, ao pedido de Natássia de que Linda pudesse, então, deixar de ser sua nutricionista para que elas pudessem se relacionar como iguais fora do ambiente hospitalar.

Ser uma pessoa "normal", nesse fragmento, pareceu equivaler a não ocupar o lugar de profissional. Se no contexto de atendimento do serviço em questão, o discurso que preconiza a distância necessária entre 0 profissional e o paciente teve como efeito o afastamento entre Natássia e Linda; fora dele a dupla poderia se reaproximar. Não obstante, o entendimento de Linda sobre a "ética" envolvida no relacionamento do profissional com o paciente levou-a a se posicionar contra tal sugestão. Para Linda, o formato da relação entre o paciente e o profissional se estenderia para fora dos muros do hospital, sendo assim, não seria possível que Natássia ocupasse outro lugar que não o de paciente. O "ódio" à condição de fragilidade do laço apareceu no trecho selecionado como provável repúdio à marcação de lugares fixos que circunscrevem limites de relacionamento. $O$ sentido para o TA, nesse momento, foi o de ser impeditivo para que um relacionamento mais intenso entre pessoas "normais" prosperasse.

Ao mesmo tempo, outro sentido para a BN emergiu nesse segmento narrativo, contrastando com o sentido anterior. A BN como um trunfo que estaria sob o controle de Natássia, como algo que ela poderia optar por não ter mais, se o desejasse. $O$ apelo por um modelo de relacionamento distinto e exclusivo com a nutricionista, nesse momento da entrevista, surge como a solução que abriria a possibilidade de Natássia obter a cura de seu problema.

Se nos limites circunscritos pelo relacionamento com Linda, Natássia não podia manter-se próxima da profissional, com Teresa isso não acontecia. Informada por sentidos éticos distintos, a profissional conseguiu oferecer a Natássia espaços de acolhimento e conversa; porém Natássia reagiu a essa proximidade oferecida por Teresa de forma surpreendente, ao afirmar que fez, ela própria, o corte dessa relação, ao deixar de ser responsiva. Como membro do contexto discursivo que constrói a adequação e inadequação das posturas assumidas pela categoria profissional, Natássia disse ter ficado em dúvida sobre se a manutenção de uma relação tão próxima com a psicóloga seria positiva. Também afirmou que temia que tamanho investimento afetivo nessa relação pudesse tornar ainda maior a dor advinda de uma eventual perda de contato, caso 
a mesma vicissitude que ocorrera com Linda acontecesse com Teresa.

No modelo consagrado de relacionamento entre o profissional e o paciente a necessidade de estar em tratamento de alguma patologia seria condição sine qua non para que Natássia e Linda pudessem permanecer juntas. Desse modo, a possibilidade de receber "alta" do serviço é significada como algo que cindiria esse vínculo. Nessa lógica, uma profissional permitir, como fez Teresa, uma relação de "apego" com o paciente para além dos limites tidos como aceitáveis pelos códigos de conduta vigentes acabaria por dificultar a necessária separação entre profissional e paciente ao término do tratamento. Não obstante, Teresa, em decorrência da diferença de seu posicionamento ético, entendia que as duas poderiam continuar se encontrando fora do ambiente institucional.

Natássia afirma que a postura de Teresa talvez não fosse a mais valorizada no serviço. Ao empregar o termo "top", Natássia se referia a algum profissional hierarquicamente superior a Teresa no serviço, que teria o poder de decidir sobre como os profissionais deveriam se relacionar com os pacientes no ambulatório. Considerando o contexto de produção dessa entrevista, falar sobre o "segredo" que envolvia seu relacionamento com Teresa era contar para outra profissional do serviço sobre uma possível violação da forma eticamente correta de um psicólogo se portar.

Segundo Natássia, em seu relacionamento com Teresa, não apenas a psicóloga necessitava dela, mas também o inverso acontecia. Desse modo, a simetria estaria garantida pela convergência das necessidades. Quando Natássia entrou naquilo que ela própria chamou de "crise", isto é, o temor de que Teresa também fosse deixá-la um dia, conseguiu manter o controle de suas emoções e não se desesperar, ao imaginar que teria um espaço de "conversa" com a psicóloga. Aqui, a tranquilidade no relacionamento com a psicóloga nasceu de um contexto no qual a profissional conseguiu garantir meios extras de contato e proximidade com a paciente, à margem ou acima de quaisquer princípios éticos coercitivos.

\section{Talia}

O momento focalizado nessa entrevista se iniciou com a pergunta da entrevistadora sobre o que teria ajudado Talia desde que ela chegara ao serviço. Em sua resposta, a participante contou que, como Natássia, também estava vivendo o momento de substituição de nutricionistas, com o afastamento de Linda da função assistencial:

Entrevistadora: O que mais te ajudou, fora a internação? Que outras coisas que colaboraram para isso?

Talia: Foi paciência, compreensão, sabe? A paciência e a compreensão, principalmente da Linda, sabe? Porque ela não chegava e falava pra mim: "Você tem que comer assim, assim, assim". Ela mostrava a realidade pra mim das coisas. É uma tática que eu não sei como ela usava, mas que comigo caía muito bem, entendeu? Que ela conseguia, tipo, eu tô fazendo... minha nutricionista agora mudou, tipo, eu senti muito, porque não é a mesma assim, sabe? Foram táticas de tantos anos, então, eu tenho medo. Medo de a gente conversar dos alimentos. Com essa nutricionista [nova] eu tenho medo, com a Linda não, ela olha na minha cara: "Quê que tem? E daí?". Tipo, com uma naturalidade, como se... E com essa já não, com essa eu já me prendo mais. Então, é uma tática que eu não sei te explicar como é, mas que só o jeito dela...

Entrevistadora: É segurança que passa?

Talia: É, muita segurança. Tipo, muita segurança: "Eu tô com você e você tá comigo, nós duas aqui, minha filha, você não vai sair recuperando peso assim não, confia em mim e eu confio em você", entendeu? Uma segurança enorme e... E ela não mostra medo nos alimentos também. Ela mostra que os alimentos é coisa natural. Agora, eu não sei, eu não posso criticar, porque eu já tive uma,.. uma consulta só com essa nutricionista nova, então eu não sou ninguém para criticar ninguém, ela tá fazendo o lado dela, e ela é uma ótima profissional, porque eu creio que eles não iam colocar um profissional ruim aqui. Só que eu tenho que me encaixar, mas eu não tô me encaixando não.

Entrevistadora: Todo vínculo demora, né? Pra gente confiar em alguém, né?

Talia: Demora um pouco. 
Entrevistadora: Com qual profissional você tem uma relação mais positiva e como que ele te ajuda? Nessa relação com a Linda?

Talia: É. A Linda. Essa relação de amizade, não é amizade, não tô dizendo que nós somos amigas, nós somos, como, uma palavra... A gente é, ela uma profissional que... que, ela tem muito carinho pelos pacientes e acho que assim, ela... ela, ela não vive só aqui dentro do hospital. Eu acho que ela leva, pensa nos pacientes dela a hora que ela tá sozinha, ela pensa, ela pensa como tentar ajudar, como melhorar, como, por exemplo, quando eu precisava tomar um suplemento [alimentar]... Eu não tinha nenhuma consulta com ela, ela trouxe: "Talia, eu preciso falar com a Talia", ela trouxe um caderninho pra mim, chegou lá na sala dela e falou: "Você pode fazer isso, fazer essa receitinha que é muito boa. Ela se preocupa com os pacientes, ela... então, tudo que ela tem agora, se ela conseguiu isso na profissão [mudar de posição dentro do serviço] foi por mérito dela, da dedicação dela, entendeu? Porque ela sempre foi uma pessoa muito, muito presente no que ela fazia.

As "táticas", descritas como parte do "jeito" de ser da profissional, seriam, segundo Talia, uma característica pessoal de Linda, algo que não se pode "explicar". Dessa forma, aquilo que aconteceu de positivo entre as duas estaria localizado em algo que Linda "era" ou "fazia", e não em algo que as duas faziam juntas ou algo que outra nutricionista poderia também reproduzir. Dificilmente outra pessoa poderia reunir as mesmas qualidades excepcionais de Linda. $\mathrm{Na}$ fala da entrevistadora, a segurança apareceu como sentido suplementar para o relacionamento de Linda com Talia. Talia, na sequência interativa, respondendo ao sentido oferecido pela entrevistadora, narrou o relacionamento entre ela e Linda como algo que nasceu da confiança que a profissional solicitou que Talia depositasse nela.

A confiança depositada na equipe, de que não iriam "colocar uma profissional ruim" no novo atendimento, participava desse momento de significação da substituição de sua nutricionista. $\mathrm{Na}$ afirmação da entrevistadora de que "todo vínculo demora" para se processar foi oferecido o sentido da relação entre o profissional e o paciente como uma ligação emocional que se intensifica com o decorrer do tempo e que requer paciência e confiança para se consolidar. A partir do uso desse sentido, a entrevistadora se posicionava como capaz de compreender a dificuldade de Talia de se desvincular de sua nutricionista. A autocorreção que Talia fez quanto ao uso do termo amizade pareceu estar relacionada ao conflito entre as diferentes posturas socialmente esperadas: uma para 0 relacionamento entre o profissional e o paciente, e outra, para um relacionamento entre amigos. No primeiro caso, como argumentado anteriormente, uma postura de um certo distanciamento seria necessária para garantir a objetividade da avaliação e a eficácia do atendimento oferecido, ao passo que, no segundo caso, a afinidade e proximidade afetiva entre as pessoas seria uma das principais marcas para aquilo que é designado pelo senso comum como amizade.

Outro sentido atribuído à postura de Linda por Talia foi o de expressar "preocupação" com os pacientes. Tal sentido foi construído em contraposição ao discurso de neutralidade do profissional. Diferentemente do que esse discurso apregoa, nesse momento a preocupação foi justamente o que agregou valor a Linda como profissional, justificando inclusive o crescimento profissional da nutricionista dentro do serviço. Assim, o sentido construído para a substituição de Linda foi o de "mérito", conferido pela "dedicação" demonstrada pela nutricionista aos seus pacientes.

\section{IIda}

Ao contar sobre os relacionamentos significativos que mantinha com alguns profissionais da equipe, Ilda mencionou a abertura que sentia nas conversas com seu psiquiatra, um profissional que a atendia em contexto privado e não fazia parte da equipe do serviço de assistência em TA. A entrevistadora perguntou sobre o que contribuía para que essas conversas se tornassem positivas.

Entrevistadora: Mas só pra voltar naquilo - que eu achei importante - o que te ajudou a falar com o Carlos [psiquiatra] naquele momento?

Ilda: Eu senti uma... uma confiança, eu senti um apoio, uma sensação de... como é que fala?- Interesse em você, carinho. Eu achei que ele veio, ele pegava na minha mão, o contato físico é 
muito importante. Não, assim, que eu fosse interpretar de outra forma, não! Não é aquele contato que você entende de outra forma, não é o contato que você tá, é, com interesse pelo sexo oposto, vamos dizer. Não é assim. É assim, um contato físico, ele me dava a mão, ele segurava, ele me cumprimenta. Até hoje ele me dá três beijinhos, ele... assim, não que eu vá confundir isso com outras coisas, mas assim eu acho que o contato, o carinho, a preocupação com você... Porque o pessoal da equipe, tipo assim, médico, a equipe médica, e às vezes, a nutricionista - a nutricionista um pouco menos - mas, assim, o médico, ele é muito mais frio, ele pensa mais no objetivo dele que é tratar a doença, assim, dos sintomas. Ele quer atuar sobre os sintomas, para que você não morra, ele quer que você não morra de inanição.

A separação entre os profissionais "frios" e "não frios" foi construída na fala de Ilda, primeiramente, a partir da possibilidade de o profissional ter um "contato físico" com o paciente, incluindo "pegar na mão" e "cumprimentar com um beijo". Esses gestos foram associados por Ilda com uma "sensação" de "confiança", "interesse" e "carinho" por parte do profissional. Quando diferenciou essa proximidade física de um relacionamento do tipo homem e mulher, Ilda pareceu fazer a distinção, frequente nas práticas discursivas cotidianas, entre o tipo de comportamento que é próprio e adequado a um relacionamento profissional e a um relacionamento pessoal, ou seja, tradicionalmente o campo das relações entre o profissional e 0 paciente solicita maior formalidade e neutralidade, para supostamente assegurar a precisão das condutas profissionais.

O segundo aspecto que diferenciaria os profissionais "frios" dos "não frios" seria que os primeiros focalizariam sua atenção no bem-estar do paciente, valorizando o acolhimento, e não apenas o transtorno mental e seu tratamento, postura descrita por Ilda como centrada no objetivo. Ilda associou a maior proximidade do profissional em relação ao paciente com o fato de ser uma "conversa sobre o lado emocional". Falar de emoções, nesse sentido, seria algo mais facilmente identificado com a função de um psiquiatra, sendo que nutricionistas e nutrólogos, por exemplo, incluiriam tal abordagem apenas em circunstâncias excepcionais.

\section{DISCUSSÃO}

Embora os argumentos a favor de um contato mais íntimo com os profissionais não devam ser vistos fora de seu contexto de produção, podemos dialogar sobre de que modo o discurso da neutralidade pode impedir um formato de relacionamento entre o profissional e o paciente que poderia, de maneira mais direta, atender às necessidades das pacientes (Camuri \& Dimenstein, 2010; Macedo \& Dimenstein, 2009). O tema da afetividade no relacionamento entre o profissional e o paciente ainda é evitado nos debates em saúde (Fernandes, 2003). No campo dos TAs, a autenticidade e segurança afetiva no âmbito do relacionamento entre o profissional e o paciente são cada vez mais expostas como importantes recursos para reabilitação dos pacientes (Wright \& Hacking, 2012).

Poderíamos perguntar sobre quais seriam os efeitos de perceber a demanda de Natássia por proximidade com a nutricionista Linda de forma mais relacional, e não como uma suposta distorção de sua personalidade, entendendo a quem serve a neutralidade na postura profissional. Aqui cabe fazer uma ressalva para que essas necessidades possam ser entendidas também como construções sociais. A demanda pela "amizade" com uma nutricionista ou a satisfação pelo "contato mais íntimo" com o psiquiatra, como apontado por Ilda, podem ser entendidas como decorrentes da eleição do tratamento como locus exclusivo das trocas sociais realizadas por essas pacientes.

$\mathrm{Na}$ voz dos profissionais, presentificada nas narrativas das participantes, evitar a proximidade afetiva com a paciente é uma postura ética a ser preservada. Como mencionado, ética aqui é entendida como necessidade de delimitar as posições no interjogo relacional, deixando claras as funções do profissional e diferenciando-as das do paciente. Nesse jogo de posicionamentos, o profissional ocupa um lugar de suposto saber e tem um papel social específico e diferenciado, por exemplo, do papel de amigo. Um profissional de saúde teria o compromisso com a verdade do que "é" a doença e do que seria bom e recomendável para o seu tratamento (Souza \& Santos, 2009), sendo que, como visto no estudo de George (1997) e de Rabinor (2004), uma maior proximidade entre ele e o paciente só deveria ser ofertada se esse 
tipo de envolvimento emocional fosse considerado como terapêutico.

Ética, nesse modo de entender, é um compromisso contraído pelo profissional como representante de um saber científico, sendo ciência aqui entendida como o campo da descoberta de verdades universais - portanto, inquestionáveis. As inteligibilidades pósmodernas, por sua vez, propõem uma noção ética distinta. Quando se entende que não existe uma única verdade aceitável sobre o mundo, mas verdades situadas em contextos de produção local, os repertórios interpretativos disponibilizados pelo discurso científico moderno passam a ser vistos como algumas possibilidades para a produção de sentidos em saúde (Souza \& Scorsolini-Comin, 2011; Spink, 2010). O sentido de ética como ética relacional (Gergen, 2009), e não individual, é uma das propostas que se abrem para pensar as relações entre o profissional e o paciente no âmbito da assistência em AN e BN. Nesse entendimento, ética é proposta como uma arena de negociações, em que a decisão sobre o que vai ser considerado correto e útil parte de um movimento dialógico, ou seja, se constitui na relação, no momento interativo.

A legitimação do profissional como responsável pela defesa do bem-estar do paciente ajuda a entender a fala de Talia de "ter que se encaixar" na relação com a nova nutricionista proposta pela equipe. A partir desse modelo, ao qual seria necessário se ajustar, o comando do tratamento manter-se-ia no domínio da especialização profissional. Gomes, Nations, Sampaio e Alves (2011) apontam a necessidade de modificar essa lógica, posicionando o paciente como sujeito ativo e corresponsável pelo alcance de sua melhora, o que garantiria sua participação em todas as decisões do tratamento. Caso contrário, como menciona Fernandes (2003), em nome de uma neutralidade científica, não haverá espaço no relacionamento entre o profissional e o paciente para o exercício político do profissional como capaz de olhar para o contexto macrossocial no qual esse relacionamento se insere e para as relações de poder que ele instaura.

Os profissionais descritos por Ilda pareceram buscar responder aos sentidos sobre o cuidado em saúde a partir de uma concepção teórica de ser humano que concebe a mente e o corpo como objetos de investigação estanques (Pessotti, 1996). A alienação profissional responde à mencionada formação acadêmica do aluno de medicina, que padroniza os pacientes (Pessotti, 1996), aprisionando-os em rótulos diagnósticos. Segundo Caprara e Rodrigues (2004), a tecnologia foi incorporada à profissão médica de forma a deixar de fora a consideração dos aspectos subjetivos do relacionamento com o paciente. Gomes e cols. (2011) afirmam que a valorização da técnica, a busca pela especialização e a racionalidade diagnóstica desviaram o olhar do profissional da saúde, especialmente o do médico, para a subjetividade do paciente, aumentando a distância entre eles e indo à contramão dos princípios propostos pelo Sistema de Saúde Brasileiro (SUS), que vê nesse relacionamento a principal estratégia de promoção da saúde. Como informa Sucupira (2007), o relacionamento entre o profissional e o paciente não pode ser visto como uma técnica a ser seguida por meio de protocolos, mas como um processo relacional promotor de transformações sociais. Como afirma Merhy (2002), é justamente no espaço de encontro entre o profissional de saúde e o paciente, com o uso das tecnologias relacionais, que é possível o profissional encontrar resistência à imposição das forças instituintes no trabalho em saúde (como, por exemplo, a imposição sobre como a afetividade deve ser vivida no relacionamento entre o profissional e o usuário) para o exercício de sua criatividade na produção de cuidado.

\section{CONSIDERAÇÕES FINAIS}

A partir do estudo empreendido, podemos tecer algumas considerações sobre o pedido feito pelo paciente com TA de proximidade afetiva com o profissional da saúde. Uma delas tem relação com a problematização do efeito da disponibilização dos repertórios interpretativos sobre o relacionamento entre o profissional e o paciente na literatura científica sobre TA, quando se busca entender todo e qualquer paciente a partir dessas pautas normativas. Nessa generalização, as dificuldades construídas no relacionamento entre profissional e paciente podem ser narradas como decorrentes das características desviantes de personalidade dos pacientes, sem que se abra espaço para a legitimação de outras explicações possíveis a respeito da origem dessas dificuldades. Pensar o diagnóstico como construção social nos ajuda a entender que qualquer nomeação do que é 
saudável ou doentio nasce de acordos sociais historicamente pontuados.

Outra consideração a ser feita relaciona-se à possibilidade de os profissionais de saúde entenderem a proximidade afetiva com o paciente não como algo a ser julgado como bom ou ruim a priori, antes do estabelecimento dessa relação, mas como algo a ser avaliado a partir do contexto relacional instituído. Dessa forma, as normas e limites para o relacionamento devem ser definidos a partir dele. A voz do paciente deve ser ouvida para a definição do que vai ser considerado um bom relacionamento.

Por fim, quando pensamos promoção de saúde como cuidado oferecido não apenas no tratamento de doenças, podemos questionar em que medida o estabelecimento de um tratamento ambulatorial para assistência em TA é capaz de oferecer intervenções focadas não apenas na superação dos sintomas da $\mathrm{AN}$ e $\mathrm{BN}$, mas endereçadas também à reinserção social do paciente e ao restabelecimento de sua condição de ser saudável no mundo. Este ainda é um desafio para o campo de atuação na área, que prioriza o diagnóstico como parâmetro para as ações em saúde e acaba compondo uma relação com o paciente na qual este tem que se manter doente para poder receber cuidado.

\section{REFERÊNCIAS}

Bruch, H. (1978). Golden cage: the enigma of Anorexia Nervosa. Cambridge: Harvard University Press.

Brusset, B. (2003). Conclusões terapêuticas. In B. Brusset, C. Couvreur, \& A. Fine (Orgs.), A bulimia (pp. 173-184) (M. Seincman, Trad.). São Paulo: Escuta.

Camuri, D., \& Dimenstein, M. (2010). Processos de trabalho em saúde: práticas de cuidado em saúde mental na estratégia saúde da família. Saúde e Sociedade, 19(4), 803-813.

Caprara, A., \& Rodrigues, J. (2004). A relação assimétrica médico-paciente: repensando 0 vínculo terapêutico. Ciência \& Saúde Coletiva, 9(1), 139-146.

Fernandes, J. C. L. (1993). A quem interessa a relação médico-paciente? Cadernos de Saúde Pública, 9(1), 21-27.

George L. (1997). The psychological characteristics of patients suffering from anorexia nervosa and the nurse's role in creating a therapeutic relationship. Journal of Advanced Nursing, 26(5), 899-908.
Gergen, K. J. (2009). Relational being: beyond self and community. New York: Oxford University Press.

Gomes, A. M. A., Nations, M. K., Sampaio, J. J. C., \& Alves, M. S. C. F. (2011). Cuidar e ser cuidado: relação terapêutica interativa entre o profissional e o paciente na humanização da saúde. Revista APS, 14(4), 435-446.

Hepworth, J. (1999). The social construction of anorexia nervosa. London: SAGE Publications.

Jeammet, P. (2003). Desregulações narcísicas e objetais na bulimia. In B. Brusset, C. Couvreur, \& A. Fine (Orgs.), A bulimia (pp. 103-136) (M. Seincman, Trad.). São Paulo: Escuta.

Macedo, J. P., \& Dimenstein, M. (2009). Psicologia e produção do cuidado no campo do bem-estar social. Psicologia e Sociedade, 21(3), 293-300.

Merhy, E. E. (2002). Saúde: a cartografia do trabalho vivo. São Paulo: Hucitec.

Pessotti, I. (1996). A formação humanística do médico. Medicina, 29, 440-448.

Pettersen, G., \& Rosenvinge, J. H. (2002). Improvement and recovery from eating disorders: a patient perspective. Eating Disorders, 10(1), 61-71.

Rabinor, J. R. (2004). The therapist's voice. Eating disorders, 12(4), 361-365.

Satir, D. A., Thompson-Brenner, H., Boisseau, C. L., \& Crisafulli, M. A. (2009). Countertransference reactions to adolescents with eating disorders: relationships to clinician and patient factors. International Journal of Eating Disorders, 42(6), 511-521.

Souza, L. V. (2011). Construindo cuidado: relacionamento com profissional de saúde nas práticas discursivas de pessoas diagnosticadas com transtornos alimentares. Tese de Dourtorado, Faculdade de Filosofia,Ciências e Letras de Ribeirão Preto, Universidade de São Paulo, São Paulo.

Souza, L. V., \& Santos, M. A. (2009). A participação da família no tratamento dos transtornos alimentares. Psicologia em Estudo, 15(2), 285-294.

Souza, L. V., \& Scorsolini-Comin, F. (2011). Relações profissionais em equipes de saúde: alternativas construcionistas relacionais. Saúde e Transformação Social, 1(3), 37-46.

Spink, M. J, P. (2000). A ética na pesquisa social: da perspectiva prescritiva à interanimação dialógica. Psico, 31(1), 7-22

Spink, M. J. P. (2010). Social psychology and health: assuming complexity. Quaderns de Psicologia, 12(1), p. 7-21.

Spink, M. J. P., \& Medrado, B. (2000). Produção de sentidos no cotidiano: uma abordagem teórico-metodológica para análise das práticas discursivas. In M. J. P. Spink (Org.), Práticas discursivas e produção de sentidos no cotidiano: aproximações teóricas e metodológicas (pp. 41-61). São Paulo: Cortez. 
Sucupira, A. C. (2007). A importância do ensino da relação médico-paciente e das habilidades de comunicação na formação do profissional de saúde. Interface: Comunicação, Saúde, Educação, 11(23), 619-635.

Tantillo, M. (2004). The therapist's use of selfdisclosure in a relational therapy approach for eating disorders. Eating disorders, 12(1), 51-73.

Williams, M., \& Leichner, P. (2006). More training needed in eating disorders: a time cohort comparison study of Canadian psychiatry residents. Eating Disorders, 14(4), 323-334.
Wright, K. M., \& Hacking, S. (2012). An angel on my shoulder: a study of relationships between women with anorexia and healthcare professionals. Journal of Psychiatric and Mental Health Nursing, 19(2), 107-115.

Recebido em 16/08/2011 Aceito em 18/12/2012

Laura Vilela e Souza: professora adjunta do Departamento de Psicologia do Instituto de Educação, Letras, Artes, Ciências Humanas e Sociais da Universidade Federal do Triângulo Mineiro.

Manoel Antônio dos Santos: professor associado da Faculdade de Filosofia, Ciências e Letras de Ribeirão Preto, Departamento de Psicologia da Universidade de São Paulo, bolsista de produtividade em pesquisa do CNPq. 